\title{
The 18th European Doctorial Converence in Nursing Science - EDCNS
}

\author{
19.-21. September 2019, Graz
}

Online publiziert: 19. September 2019

(C) Springer-Verlag GmbH Austria, ein Teil von Springer Nature 2019

\section{ABSTRACTS}

\section{Abstracts keynote speakers}

\section{„Making Impact in the Real World: How We Make Our Research Count“"}

\section{Prof. Dr. Gordon A.}

University of Nottingham; United Kingdom

Researchers can often face existential crises about the purpose of their work. Members of the public often state uncertainty about the difference that research makes. This lecture will consider an approach to address these concerns by focussing on routes to real world impact in research. It will describe the first (bench to trial) and second (trial to clinic) translational gaps and describe how these are bridged. It will look at structured approaches to research impact, focussing on economic and societal, as well as academic impact. It will consider approaches that researchers can take to ensure their work influences: policy, practice and service provision (instrumental impact); understanding and the public debate (conceptual impact); and the availability of researchers and clinicians with the necessary technical and personal skills (capacity impact). Each of these will be discussed with examples of real world research studies and the difference they have made, with a view to encouraging academics to think carefully about their approach to current and future projects, to maximise the difference they make in the real world.

\section{„The Living Lab in Ageing and Long-Term Care; a model for collaborative research"}

\section{Prof. Dr. Hamers J.}

Maastricht University; the Netherlands

This lecture presents a model for a sustainable and successful interdisciplinary collaboration between scientists, care providers, and educators in long-term care: the „Living Lab in Ageing and Long-Term Care“. For over 20 years this structural collaboration has served as an infrastructure that drives scientific research in long-term care in co-creation with end-users, including older people and their relatives, health care professionals, policy makers and educators. The aim of the Living Lab will be described, the key working mechanisms of the interdisciplinary collaboration will be explained, and the scientific and societal impact will be highlighted.

\section{„The Meaning of Nursing Theory for the Future of Nursing"}

\section{Prof. Dr. Zumstein-Shaha M.}

University of Applied Sciences; Switzerland

Nursing theory remains contentious as applicability and relevance are questioned and critiqued regularly. Additionally, concepts such as evidence-based nursing and theory-based practice remain ideals with a marginal implementation into practice. Within rapidly changing healthcare systems, the meaning of nursing theory for practice and for the future is difficult to determine. This presentation aims at identifying the meaning of nursing theory for practice and the future. Literature will be consulted and thematically analysed to address this aim. It will be demonstrated that progress of nursing science, improvement of practice and guidance for the future can only be achieved through the appreciation and development of nursing theory. 